\title{
Obra Criada no Âmbito de um Contrato de Trabalho. Obra sob Encomenda.
}

\author{
Antônio Chaves \\ Catedrático de Direito Civil da Faculdade de Direito \\ da Universidade de São Paulo.
}

\section{Introdução.}

A necessidade sentida em cada país, à medida que os criadores e os próprios usuários de obras intelectuais se tornam mais exigentes na defesa de suas prerrogativas, de aperfeiçoar a "engrenagem" do seu direito de autor, por meio de sucessivos reajustes, que a coloquem em harmonia com os progressos da técnica, não poderia deixar de sofrer reflexos rıa ordem internacional sabido como é que o aperfeiçoamento das providências legislativas de caráter interno, por não terem qualquer eficácia além fronteira, podem ser gravemente prejudicadas quando aí não encontrem a indispensável correspectividade.

O maravilhoso e delicado cronometrismo do desempenho do direito de autor faz, por outro lado, com que, quando determinado assunto esteja amadurecido pelo menos em algumas legislações mais avançadas, surja a oportunidade de incorporar, nas grandes convenções internacionais, complementações que correspondam a uma dupla finalidade: $1 .^{\mathrm{a}}$, estabelecer o necessário equilíbrio no entrechoque dos interesses

\footnotetext{
*. Tese apresentada à Comissão Jurídica e de Legislação da "Confédération Internationale des Sociétés d'Auteurs et Compositeurs" (CISAC), em sua reuniāo de Jerusalém, de 11 e 12 de maío de 1976.
} 
opostos; 2. a, limitar a liberdade dos legisladores internos menos avisados de tomarem providências que tenderão logo a se radicalizar, tornando-se, depois, difíceis de modificar

Um exemplo bem expressivo desta verdade encontra-se na atual regulamentação das obras criadas, bastante diferenciada, no âmbito de um contrato de trabalho e das obras sob encomenda, cujos direitos autorais algumas legislações reconhecem caberem aos seus criadores, outras o atribuem aos empregadores, e outras dividem meio a meio. Grande número deixa ainda campo aberto para inteira regulamentação aos interessados, o que significa, em última análise, que o empresário tomará a decisão que o legislador não teve a coragem de impor, e, é claro, sempre a seu favor.

Poder-se-ia pensar em tentar uma consolidação dos textos legislativos de caráter interno relativos à matéria. Seria porém repetitivo ou contraditório. Mais útil, portanto, do que insistir no percurso de seus labirintos, procurar deduzir, dos melhor inspirados; com os complementos que possa proporcionar a escassa doutrina pertinente, uma orientação plausível.

$\mathrm{O}$ único ponto de partida, que oferece a firmeza inabalável de um alicerce cravado na rocha viva da verificação de um fato, com a expressividade simples de um preceito bíblico, que não se desgasta pela repetição milenária, é o que se pode deduzir do art. 1, da lei inglesa de 1956: quem cria uma obra será titular de qualquer direito que ela possa proporcionar.

Podemos daí partir para a análise de vários desvios que, como hervas daninhas brotam nas frinchas de algumas leis, e que um jardineiro zeloso se esforçará por extirpar, antes que deitem raízes e floresçam em novas sementeiras.

E o caso de algumas legislações que, genericamente, atribuem a paternidade ao empregador, quando semelhante circunstância em nada interfere no fato material da criação, a não ser naqueles casos, proporcionalmente raros, em que é 
cle mesmo quem dá a idéia, fornece instruções minuciosas, materiais, elementos criativos e de pesquisa, auxiliares e subsídios. Apenas nessa hipótese, bastante rara, a sua contribuição se eleva à dignidade de uma verdadeira colaboração, quando não de verdadeira autoria, não passando o empregado de um executor fiel, de um operário qualificado.

\section{Obra criada no âmbito de um contrato de trabalho.}
A relação de emprego não retira a titularidade do do criador da obra.

Com exceção da eventualidade mencionada, são duas, fundamentalmente, as diferenças entre as obras literárias e artísticas criadas espontaneamente e as feitas mediante relação de emprego ou sob encomenda.

A primeira consiste em que, nestas, é o seu autor quem escolhe $o$ assunto e o desenvolvimento, ao passo que, naquelas, de certa forma é o inverso que ocorre, no sentido de que, determinando o tema que lhe interessa, é o empresário que, entre vários autores em potencial, procurará aquele que, por suas aptidões e inclinações, tenha melhores possibilidades de proporcionar-lhe or resultado objetivado.

Enquanto, ainda, na segunda eventualidade, é o autor quem tem a iniciativa de colocar a sua produção indistintamente à disposição de todos os eventuais consumidores, na primeira é um só destes que se separa da massa indeterminada, para, mediante remuneração adequada, obter a exclusividade, num primeiro passo, da obra intelectual, que, depois, por seu intermédio, irá cumprir o seu destino normal de entrar em contacto com o público.

A separação resultará menos acentuada quando se reconheça que tudo se reduz a uma interposição do empregador ou de quem faz a encomenda entre o autor e o público, cujo relacionamento deixa então de ser feito por intermédio dos 
costumeiros editores, gravadores, etc., substituindo o empresário o risco dos resultados financeiros, pela remuneração convencionada.

Alcançado, no entanto, o objetivo da contratação, exaurida para cada contribuição exigida do autor, a obrigação do mesmo, tudo tende a voltar à normalidade, não havendo razão que justifique tratamento muito diferente do normal, como revela a circunstância que nenhuma lei se anima a negar que apenas os atributos econômicos foram cedidos ao empresário, ficando ao autor todos os de ordem moral.

Apartam-se, então, nitidamente, os dois campos: quem encomendou ou custeou a obra obtém a cessão da parte patrimonial do direito, mas, é importante assinalar, para aquela finalidade especificamente convencionada, dispensada autorização, que é implícita, para o aproveitamento normal e imediato, sem cogitar de outra remuneração a não ser a combinada.

Terá, no entanto, de ser ressalvado qualquer aproveitamento ulterior, seja mediante simples reiteração da primeira modalidade, seja mediante tradução, adaptação, transformação, etc., que deverão ser precedidas da necessária autorização e da competente retribuição, sem se entrar em indagações sobre se a obra é ou não de valor excepcional.

Obedecendo a provocações de determinados setores mais ativos, propende o legislador nacional demasiado número de vezes para emanar regras dirigidas a determinada entre muitas manifestações literárias ou artísticas, sem aproveitar a oportunidade para lançar uma vista a todas, conjuntamente.

Daí resulta, fatalmente, uma regulamentação ao mesmo tempo assistemática e falha.

Acresce que alguns trabalhos realizados sob vínculo empregatício não ficam aguardando do legislador a solução adequada, antecipando-se a ela. E o caso da produção cinema- 
tográfica, cujas características foram se definindo pela reiteração, sedimentando determinadas práticas, como a de, sem embargo dos altos ordenados que percebem, os artistas principais, compartilharem ainda do resultado econômico da empreitada.

Embora qualquer obra possa ser criada no âmbito de um contrato de trabalho, dentre as muitas que possam ser lembradas separemos duas, que por suas características mais simples, facilitarão o equacionamento das demais:

\section{a. A obra jornalística ou periodística.}

Haverá realmente que distinguir entre o trabalho feito espontaneamente, e remetido à redação de um jornal, de uma estação de rádio e televisão, pelo interessado, para eventual aproveitamento, e o trabalho realizado por redator estipendiado?

Já vimos que o vínculo empregatício não altera a paternidade da criação: é o resultado, a obra que interessa. Sobre cla e não sobre o criador, ou a sua condição de empregado ou não, deve o legislador concentrar os seus cuidados. Confirmará então não haver razão para que seja diferente a regulamentação da matéria: se o "corpus" pertence a quem encomendou a obra, também aqui deve prevalecer o princípio de que, com o aproveitamento, esgota-se o direito de quem fez a encomenda: qualquer ulterior aproveitamento, diretamente ou por meio de gravação, qualquer adaptação ou tradução, terá de ser precedida de autorização expressa.

Obra realizada x pagamento. Aí estão os dois polos da relação convencionada. Qualquer ulterior aproveitamento será contrato diferente, exigindo novo entendimento, e, obviamente, o complemento de uma nova retribuição.

A razão é a mesma: a remuneração do primeiro aproveitamento de toda e qualquer obra, independentemente do fato 
de ter surgido sob relação de emprego, não autoriza utilizações ulteriores não recompensadas.

Longe de entregar o assalariado à mercê do empregador, esforçar-se-á o legislador nacional, e, ainda mais, o internacional, no sentido de procurar diminuir o desequilíbrio de forças. Respeitadas as características do contrato, a qualquer ulterior aproveitamento da obra, mesmo reiterado, ainda que pelo mesmo empregador, deve corresponder uma adequada posterior compensação, de modo que a vantagem não reverta exclusivamente em benefício do empresário, mas reservando-se dos lucros por este auferidos pelo menos uma percentagem irrenunciável em favor do empregado.

Nem parece seja plausível estabelecer, como faz a lei da África do Sul, distinção entre a obra feita por aprendiz daquela trazida à luz por autor veterano.

Admitir-se que o critério possa favorecer oportunidades de trabalho para iniciantes, há que se reconhecer a eventualidade de um destes realizar trabalho de alto mérito, ou que, simplesmente, alcance inesperado favor público. Não há razão para enriquecer o empresário sem que este fique obrigado a retribuir condignamente.

Mais coerente do que os dispositivos das leis como a norte-americana, a australiana, a neo-zelandeza que considecam o empregador como sendo juridicamente o autor (o que por si só revela a artificiosidade da solução) a salomônica decisão da lei brasileira, que considera pertencente o direito de cutor às duas partes.

Mas a verdadeira saída é a da terceira alínea do art. $10^{\circ}$ da lei francesa, proclamando que a existência ou a conclusão de um contrato de locação de obra ou de serviço pelo autor de uma criação intelectual não acarreta nenhuma derrogação ao gozo do direito reconhecido pela alínea $1 .^{\mathrm{a}}$. 
Isto não impede que como dispõe a lei húngara, caso a criação da obra faça parte das obrigações decorrentes de relaçäo de emprego, o empregador tenha direito de utilizar a obra cuja simples entrega importará em autorização de comunicação ao público.

Abordando o art. $10^{\circ}$ da lei francesa, aponta RoBerT Plaisant, no fascículo 6 do Juris-Classeur, de la Propriété Littéraire et Artistique, duas séries de dificuldades.

A primeira resulta do fato que a criação das obras de arte aplicada é freqüentemente tão sucessiva e difusa que não é possível determinar-lhe com segurança o autor.

A segunda, entrelaçada com a anterior, consiste em saber se o empregado, além de gozar das prerrogativas de autor, tem também o pleno exercício do aproveitamento das mesmas. Chega à conclusão de que quando diversos assalariados participam da criação com parte demasiado limitada e incerta, para que possam ser considerados como autores, semelhante qualidade deve ser reconhecida ao empregador.

Interfere porém aqui o delicado problema da cessāo dos direitos autorais. Como pode ser total ou parcial, costumam algumas leis, como a francesa, art. 35 (1) estabelecer que implicará em benefício do autor, na participação proporcional deste nos proventos decorrentes da venda ou do aproveitamento da obra, modalidade particular do "droit de suite".

Indaga o mesmo especialista, no fascículo 9, se o autor assalariado tem direito a essa participação proporcional.

Estabelecendo distinção entre o art. $1^{\circ}$ (3), que diz respeito ao gozo do direito, e o Título II, no qual se agasalha o aludido art. 35, subordinado ao aproveitamento dos direitos patrimoniais do autor, chega à conclusão, sem que haja na lei qualquer disposição contrária, que o empregador adquire o direito pecuniário na sua totalidade, em virtude do contrato de trabalho, isto é, o direito de utilizar a obra em todas as 
suas formas, originária ou derivadas. Admite, todavia, que o art. 35 não se aplica às cessões tendo por objetivo a utilização de uma obra sob forma derivada, entendendo duvidoso que se aplique aos assalariados.

No tocante ao saber-se (n. ${ }^{\circ}$ 95) quando é que estes podem ser considerados autores e ter direito à eventual participação proporcional, lembra que principalmente no domínio das artes menores, publicidade, artes aplicadas, cumpre haja realmente uma criação original, uma realização, questão de fato, suscetível de dificuldades, mas que não pode ser aludi$\mathrm{da}$, sob pena de estender indefinidamente e perigosamente o domínio do direito de autor.

Realça a dificuldade do cálculo da remuneração proporcional, compatível com adiantamentos, mas exigindo saber-se se o salário pode ser considerado como adiantamento:

"Um campo desconhecido e mais delimitado abre-se então. O problema apresenta-se particularmente quando o empregador paga, além do salário mínimo, um premio suplementar destinado justamente a recompensar o esforço de criação. Parece lógico admitir que esse premio constitui uma empreitada ("forfait"), caso esta seja admitida, ou um adiantamento, que freqüentemente ultrapassará o montante da participação proporcional."

Mas é bem nesse campo pouco versado, minado mesmo, que os comercialistas (por usurpação) entendem seu, por ser próximo ao seu feudo da propriedade industrial, que cumpre avançar, com cautela, para eliminar as dúvidas.

O problema é certamente mais delicado nos casos em que a contribuição intelectual consista numa melhoria técnica, num aperfeiçoamento no sistema de produção, numa nova combinação produzida pelo empregado no desempenho de seu mistér. 
Certamente que a tendência do empregador será toda no sentido de incorporá-la ao seu patrimônio, sob alegação de que aquele, sem a sua ajuda, o seu amparo, o seu estipêndio, não teria alcançado aquele resultado.

Ao que será fácil retrucar que não fosse a contribuição do empregado, também o amo não poderia auferir as vantagens que aquele, com a sua criação, proporciona.

Não há o que discutir: as duas peças são complementares. Terão que ser ajustadas e movimentadas em harmonia, que jamais será alcançada se houver preterição. Então será melhor ceder um pouco de cada lado, fazendo-se com que o empregado compartilhe, pelo menos em pequena percentagem, daquelas vantagens que a sua contribuição possa proporcionar ao empregador.

Nem a outra conclusão chegam dispositivos que, a exemplo da Consolidação das Leis do Trabalho brasileira, constituem o entendimento da maioria:

"Art. 454. Na vigência do contrato de trabalho, as invenções do empregado, quando decorrentes de sua contribuição pessoal e da instalação ou equipamento fornecidos pelo empregador, serão de propriedade comum, em partes iguais, salvo se o contrato de trabalho tiver por objeto, implícita ou explicitamente, pesquisa científica.

Parágrafo único. Ao empregador caberá a exploração do invento, ficando obrigado a promovê-la no prazo de um ano da data da concessão da patente, sob pena de reverter em favor do empregado a plena propriedade desse invento."

O princípio é obedecido, com desenvolvimentos pelo Código de Propriedade Industrial, inspirado pelo interesse geral, decorrente do estímulo ao espírito inventivo do empregado. 
Todavia, como observam Jacques GuéBItat e RoBert Dupuy Oeuvres créées sur commande ou en exécution d'un contrat de travail, Interauteurs, n. ${ }^{\circ} 185,1974$, pgs. 112-121, com base em um inquérito realizado pela crsac junto às sociedades-membros, este direito do empregador é adquirido para um domínio determinado e muito preciso e o autor não pode utilizar sua obra, mesmo fora dele, a não ser com o consentimento do empregador, que pode recusá-lo à utilização da obra fora do domínio previsto. Prevêm mesmo, no que concerne à remuneração do autor, deva o empregador pagarIhe de 60 a $80 \%$ dos direitos que obtém de um terceiro.

\section{b. Adaptações (obras derivadas).}

Considerar que grande parte das obras divulgadas pelo cinema, pela televisão e pelo rádio não passam de adaptações de obras pré-existentes é suficiente para demonstrar a importância da matéria.

Embora seja certo que um terceiro não poderá adaptar obra alheia sem consentimento do autor da primeira criação, indispensável ainda quando haja adaptações sucessivas (por exemplo, de uma novela para um romance, de um romance para uma peça teatral, desta para um filme cinematográfico, etc.), surgirão fatalmente problemas de ordem prática, sabido como é que a idéia não encontra ainda proteção adequada, e que só poderão ser resolvidos quando se conseguir comprovar traços dos elementos fundamentais da obra nas adaptaçōes sucessivas.

O fato pois de uma idéia ser desenvolvida de forma diferente e original nem sempre caracterizará a adaptação: não pode ser impedido, da mesma forma que não há como proibir pequenas citações e transcrições.

Já é unanimemente admitida, hoje em dia, a impossibilidade de uma salvaguarda completa do direito moral neste domínio, presumindo-se o consentimento implícito do autor 
às modificações e mutilações indispensáveis, cabendo aos tribunais pronunciarem-se quando haja abuso.

Convém, para salvaguarda dos direitos do autor, estabelecer, como se faz com o contrato de edição, um prazo dentro do qual a adaptação consentida deva ser levada a efeito, e ainda, que cada concessão deva ser objeto de contrato específico, a fim de evitar, por exemplo, que o editor de uma obra obtenha, pelo mesmo contrato, o direito de publicar, o de traduzir, o de adaptar a peça ao teatro, ao cinema, à televisão.

De qualquer modo, merece ser considerada a obrigação de reservar ao autor uma participação proporcional em todas as eventualidades de um novo aproveitamento da sua obra.

Essas considerações evidentemente não se aplicam às obras coletivas, criadas sob iniciativa de uma pessoa física ou jurídica, que a edita sob sua direção e responsabilidade.

Prevalecerá então o critério do art. 9. ${ }^{\circ}$ (3), da lei francesa, de acordo com o qual a obra coletiva criada por iniciativa de uma pessoa natural ou jurídica que a edita, publica cu divulga sob sua direção e seu nome e em que a contribuição pessoal dos diversos autores que tenham participado da sua elaboração se funde no conjunto com vistas ao qual está concebida, sem que seja possível atribuir a cada um deles um direito distinto sobre o conjunto realizado.

Nem se aplica à obra sob encomenda, mas com vários colaboradores, cada um dos quais, como ressalva, por exemplo, 0 art. 59 da lei mexicana, terá direito não apenas à respectiva remuneração, mas sendo a colaboração de natureza pessoal, original, também o de ter o seu nome mencionado.

\section{Obra sob encomenda.}

O reconhecimento amplo e irrestrito do direito do criador apresenta ainda a vantagem de dispensar a distinção entre as obras criadas em execução de um contrato de trabalho e as criadas em virtude de incumbência. 
Não haverá necessidade de repetir que, para os retratos, desenhos, gravuras etc., o corpus pertence a quem solicitou a obra, ressalvado ao autor o direito moral e o direito de pronunciar-se no que diz respeito a qualquer aproveitamento ulterior.

Para demonstrar a característica do contrato de encomenda, que consiste no fato do autor criar a obra por instigação do co-contratante, tendo em vista a remuneração que este se obriga a pagar-lhe, sem que comporte necessariamente cessão do direito de autor invoca o Professor da Faculdade de Direito de Caen, fascículo 9 bis, o exemplo da encomenda de um quadro: o pintor cede e entrega a tela, conservando porém a totalidade dos direitos pecuniários:

"O proprietário do quadro não pode exercer nenhuma das prerrogativas que comporta o direito pecuniário: direito de reprodução, direito de representação. $O$ direito de autor não intervém a não ser sob a forma do direito moral para a entrega da obra àquele que a encomendou.

Em outros casos, ao contrário, o contrato de encomenda comporta cessão de direitos de autor; é o caso do romance, do cenário, da peça encomendada a um autor para ser impressa, incorporada a um filme, levada à cena. O direito de autor intervém então sob seus dois aspectos: moral e pecuniário."

Nas obras de artes plásticas em geral, o corpus mecanicus pertence a quem encomenda a obra, sem direito, no entanto, salvo convenção expressa e remuneração adequada, de tirar qualquer proveito pecuniário, como os decorrentes de expor publicamente ou reproduzir a obra.

Merecem desaprovação, por inverterem o critério, dispositivos como o art. 80 da lei brasileira que presume, com a 
alienação da obra, a transferência ao adquirente do direito deste de reproduzi-la ou de expô-la.

Tanto mais quanto contrasta flagrantemente com o critério justo, proclamado em outros dois dispositivos legais:

o que reconhece, com relação à obra fotográfica, dois artigos depois, do direito do autor de reproduzi-la, difundi-la e colocá-la à venda, nas condições que indica, $\mathrm{e}$

o do art. 17 da Lei n. ${ }^{\circ}$ 5194, de 24.12.1966, estatuindo que os direitos de autor de um plano ou projeto de engenharia, arquitetura ou agronomia são do profissional que os elaborar, respeitadas as relações contratuais expressas entre 0 autor e outros interessados.

Se de modo contrário se procede com relação aos negativos fotográficos, é mais em obediência a uma tradição, a usos e costumes, do que a um princípio lógico, não havendo razão para aceitar-se o critério contrário, alcançando também a pintura ou o desenho de um retrato, ou uma gravura, do art. 4 (3) da lei inglesa de 1956.

E plausível o critério da lei tchecoslovaca, admitindo, aos fins da realização das obras criadas em execução de um contrato de trabalho, que qualquer organização possa, sem consentimento ulterior do autor, utilizar uma obra científica ou artística criada pelo seu empregado no âmbito de um contrato de trabalho.

Toda organização cuja atividade consista em editar ou publicar obras, não pode editar ou publicar de maneira diferente uma obra criada por empregado seu no quadro do contrato de trabalho a não ser com o consentimento do autor. Todavia, se o autor recusa sem razão plausível dar seu consentimento, dita organização poderá reclamar perante o Tribunal a autorização para editar.

A única distinção estabelecida pela lei iugoslava entre a obra decorrente de um contrato de trabalho permanente ou 
de um contrato de encomenda consiste em que, no primeiro caso, a extensão e a duração dos direitos que o empregador pode adquirir são determinados pela lei, ao passo que no segundo o legislador deixa às partes contratantes a liberdade de negociar livremente suas relações.

$\mathrm{Na}$ encomenda de um proprietário de terreno, a um arquiteto para aí construir um prédio, vêem todos um contrato de locação de serviços ou de empreitada.

Excluída qualquer idéia de cessão ou de venda - obtemperam julgados de Paris de 28.04 1921 e 08.11.1923, citados no art. 12 do fascículo 9 bis do "Juris Classeur de la Proprieté Litteraire et Artistique" - 0 arquiteto conserva a propriedade de seus planos e tem a qualidade para demandar a contrafação da sua obra, sobre a qual pode fazer valer o direito de propriedade artística desde que original e pessoal.

Mesmo para o caso mais elementar e evidente de desenhos e modelos encomendados, por exemplo, por uma estamparia, uma tecelagem ou uma casa de modas, a tendência é atribuirem-se os proventos materiais que possam proporcionar ao empregador ou a quem encomendou a obra, sem que isso impeça o reconhecimento ao desenhista ou estilista, de uma paternidade, que muitas vezes valoriza mesma a contribuiçāo.

\section{Intermediação das sociedades de direitos autorais. Contratos-tipo.}

Tal a importância que assumiram as sociedades arrecadadoras de direitos autorais, tão vasto, variado e complexo seu campo de ação, que já não se concebe possam os autores e os artistas intérpretes e executantes reivindicar pessoalmente os seus direitos.

Teimando em fazê-lo, além de se prejudicarem individualmente, por ser-lhe impossível, sem sacrifício de suas ati- 
vidades normais, administrarem satisfatoriamente seus repertórios, prejudicam-se coletivamente, estabelecendo entre si uma concorrência desastrosa e desmoralizante, jamais ficando em condições de alcançar aquele equilíbrio de forças que é sempre desejável nas partes contratantes, e ainda enfraquecem as entidades que deveriam representá-los.

Seria proveitoso fosse inserido nas convenções internacionais um dispositivo recomendando às legislações nacionais que tornem obrigatória semelhante intermediação, ou por meio dos sindicatos representativos de cada categoria, quando não haja repartição estatal ou paraestatal incumbidas, o que sem dúvida estimularia a criação dessas entidades nos poucos países onde não foram criadas, e prestigiaria as existentes.

Não há quem não perceba as vantagens que terão autores, compositores e artistas, de se valerem, além da própria união, da experiência e do prestígio de estudiosos altamente capacitados.

Deveriam mesmo, generalizando o que tantas já fazem, ser incentivadas a desenvolverem contratos-tipo, ou convenções coletivas, especificando as condições mínimas para o desempenho das diferentes modalidades: rádio, cinema, televisão, execuções musicais, edições, representações, facilitando, igualando e racionalizando a tarefa que a todas incumbe, de acordo com os respectivos estatutos, de zelar pelo interesse e pela melhor execução possível dos contratos de seus associados.

Aos próprios empresários, mais do que reivindicar prerrogativas que poderão dar margem a pleitos judiciais, interessará ver bem equacionado o problema e obter uma solução segura, e não terão dúvida, a exemplo do que ocorre nos Estados Unidos, no Reino Unido, na Iugoslávia e em tantos outros países, em reconhecer que o direito de autor deve ficar com o autor. 
Outra vantagem desse equilíbrio seria tornar inócua a controvertida "salvo cláusula em contrário", constante de tantos dispositivos da Austrália, Brasil, Finlândia, Nova Zelândia, Reino Unido, Tunísia, etc., que coloca praticamente os criadores à mercê dos empresários, alguns dos quais serão sempre tentados a aproveitar-se da abertura que essas leis lhes dão para obter dos autores renúncias aos seus direitos durante o período de duração do contrato de trabalho.

Haverá quem duvide da imoralidade de semelhante reserva? Claro que beneficiará sempre a parte mais forte: qual o editor, ou o empresário que não aproveitará a brecha que se lhe oferece, para estabelecer justamente o contrário daquilo que pretendia o bem intencionado legislador?

Será sempre um elemento altamente positivo saberem os empregadores, com certeza, que as obras criadas no exercício da atividade de seus empregados ou comissários, cessado o exercício imediato do seu aproveitamento, ou dentro do prazo ou condições previstas, são de propriedade do autor. Determinado esse ponto, passar-se-á então a discutir as modalidades de possível aproveitamento ulterior, seja pela simples reiteração do uso, seja mediante eventuais adaptações, traduções, cessões, etc., a serem feitas cada uma mediante contrato específico, mediante remuneração a ser combinada, e indicando-se expressamente os casos de resilição (falência do empresário ou situação análoga, recusa injustificada da prestação do serviço, não renovação da edição, falta de exemplares ou de representações, etc. etc.).

\section{Conclusão .}

A verificação de que é geral o reconhecimento puro e simples de que a paternidade só pode ser atribuída ao criador da obra simplifica a solução da maior parte dos problemas que possam surgir nas diferentes modalidades, eliminando a necessidade que sentem por exemplo, algumas leis, de estabelecer a ressalva de que quando a obra consista num artigo 
ou outra contribuição para um jornal ou um periódico, se deva admitir, em falta de estipulação contrária, ter o autor conservado o direito de proibir a publicação de sua obra em qualguer outro jornal, revista ou periódico análogo.

E claro que haverá casos excepcionais em que a contribuição do autor dilui-se e desaparece, quando, como já se viu, quem encomendou a obra traça as diretrizes, estrutura os planos, dá instruções e elementos minuciosos, àquele restando apenas a execução quase que mecânica da encomenda.

Mas o fato de assegurar a generalidade das legislações o direito moral ao autor da obra encomendada, ou feita no âmbito de um contrato de trabalho, não é o reconhecimento de que é a ele que cabem. com a paternidade da obra, todos os demais direitos morais?

Como conciliar as duas posições a não ser pelo reconhecimento da titularidade?

Krostermann, Das geistige Eigentbum, demonstrou cabalmente que só o criador da obra pode ser considerado sujeito originário do direito.

Desenvolvendo a idéia, faz ver Prola Caselli que, atribuindo o direito de autor a quem não tomou parte no ato criativo, não somente destruiremos a origem pessoal do direito e a sua própria justificação: violaremos a natureza daquelas faculdades pessoais que formam o conteúdo exclusivo do direito, na fase anterior à primeira publicação da obra, e permanecem, na fase sucessiva, ao lado das faculdades patrimoniais.

Ainda que o contrato de comissão acolhesse pacto implícito ou explícito de que o comitente seria considerado autor, rı̃a se poderia aceitar solução diferente:

" un tale patto, non potendo contenere il trasferimento di una qualitá o modo di essere, che non 
é di per se, trasferibile, non puó avere che significato di una simulazione, la quale potrá essere sempre impugnata da chi vi abbia interesse."

A fixação de um princípio que seja rigosamente justo, e possa ser observado com equanimidade por todos os setores interessados é de fundamental importância. Estabelecido numa convenção internacional, influenciaria beneficamente a legislação interna daqueles numerosos países que ainda não traçaram qualquer norma a propósito, e, com o tempo, tenderia a corrigir eventuais desvios nos demais.

Chega-se, pois, à conclusăo de que, da mesma forma que nas demais obras, nas sob encomenda, ou sob relação de emprego, podem e devem ser admitidas a intransmissibilidade dos atributos morais e a transmissibilidade dos pecuniários, sem qualquer ofensa ao interesse do empresário, aos princípios do direito de autor, e às vantagens para as partes intervenientes, em consonância, aliás, com o espírito das legislações internas e das convenções internacionais que partem sempre do reconhecimento dos direitos que competem ao autor pelo simples fato da criação da obra.

Percorrendo-se os dispositivos das grandes convençôes internacionais, não se encontram alusões às obras criadas por encomenda ou sob vínculo de contrato de trabalho.

Pode-se pois concluir que justamente por isso também a elas se aplicam os princípios de garantia aos autores do direito exclusivo de utilizá-las ou de autorizar sua utilização por meio de reprodução, representação, adaptação, difusão, etc.

Mas o simples fato de se apresentarem nas legislaçōes intemas casos de atribuição de paternidade da obra a quem não é seu criador, com a conseqüente transferência de todos os atributos que a este deveriam ser plenamente assegurados em qualquer circunstância, aconselha considerar-se a possibi- 
lidade de colocar nas mesmas convenções um dispositivo que, sem outra pretensão senão a de servir de base para eventuais discussões, poderia ser no sentido de que

"Os direitos reconhecidos pela presente Convenção aplicam-se às obras realizadas sob encomenda ou no âmbito de um contrato de trabalho.

Os efeitos da cessão de tais direitos exaurem-se no primeiro aproveitamento convencionado, até que o resultado obtido possa ser considerado proporcional aos dispêndios efetuados, com a margem de lucro de praxe.

Qualquer ulterior aproveitamento implicará no reconhecimento de uma percentagem nunca inferior a $20 \%$ nos lucros ou vantagens que resultem da contribuição do comissário ou do empregado." 